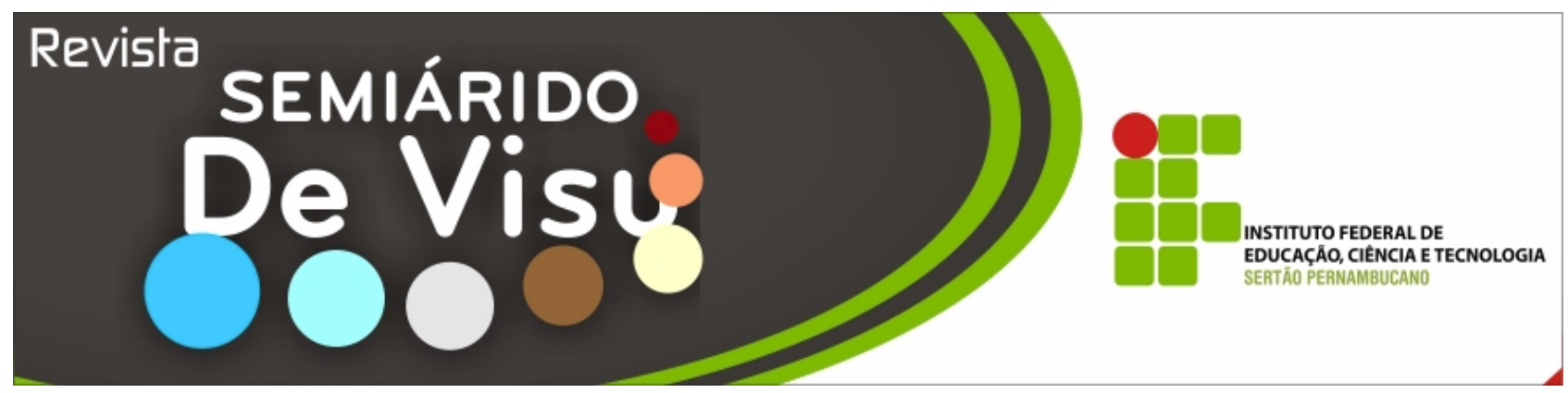

\title{
Ciência e música nas melodias da zampoña
}

\author{
Francisco Nairon Monteiro Júnior ${ }^{1}$, Liz Mayoly Muñoz Albarracín ${ }^{2}$ \\ ${ }^{1}$ Universidade Federal Rural de Pernambuco, e-mail: naironjr@hotmail.com \\ ${ }^{2}$ Universidad Distrital Francisco Jose de Caldas, Bogotá, Colômbia, e-mail: lizm200528@yahoo.com
}

\begin{abstract}
RESUMO: A análise das relações entre ciência e música pode revelar um imbricado e surpreendente mundo que, considerado para fins educacionais, pode corporificar-se em interessantes aulas de matemática e ciência do som, nas quais os elementos culturais podem ser incorporados. A construção e análise física de instrumentos musicais, bem como a criação de timbres sintetizados na música eletrônica são apenas alguns exemplos do vasto campo da acústica em que a ciência e a matemática encontram-se presentes. A utilização de tais contextos no ensino tem se tornado matéria de pesquisa nos últimos tempos. Alinhados com esta preocupação, apresentamos duas atividades, sendo uma no ensino de progressões geométricas e outra no ensino de acústica, por meio da análise de um interessante instrumento musical de origem andina, conhecido como Zampoña. Inicialmente, apresentamos a escala cromática de 12 tons, identificando-a como uma progressão geométrica. Em seguida, analisamos as notas presentes no instrumento musical, identificando o padrão de intervalos subjacente à variação do comprimento dos tubos do instrumento. Por fim, propomos a construção de um instrumento similar considerando o padrão de intervalos da escala cromática, apresentando interessantes ligações entre conceitos da acústica física e da acústica musical.
\end{abstract}

Palavras-Chave: ciência, música, zampoña, ensino de ciências.

\section{Science and music in the melodies of zampoña}

ABSTRACT: The relations between science and music can reveal a surprising and interwoven world, considered for educational purposes, can be embodied in the interesting lessons of math and science of sound, where the cultural elements can be incorporated. The construction and physical analysis of musical instruments as well as the creation of synthesized sounds in electronic music are just some examples of the vast field of acoustics where science and mathematics are present. The use of such contexts in teaching has become the field of research in recent times. Aligned with this concern, we present two activities, with a geometric progression in teaching and other education in acoustics, through the analysis of an interesting musical instrument of Andean origin, known as zampoña. Initially, we present the 12-tone chromatic scale, identifying it as a geometric progression. We then analyzed the notes present in the musical instrument, identifying the pattern of intervals underlying the variation of the length of the tubes of the instrument. Finally, we propose the construction of a similar instrument given the pattern of intervals of the chromatic scale, with interesting connections between the concepts of physical acoustics and musical acoustics.

Key-words: science, music, panflute, science teaching. 
Francisco Nairon Monteiro Júnior \& Liz Maioly Muñoz Albarracín

\section{Introdução}

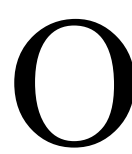

estudo dos princípios de funcionamento dos instrumentos musicais consistiu num dos mais importantes motores do desenvolvimento da acústica. $\mathrm{O}$ desvelar histórico dos mistérios da harmonia, na busca de uma explicação para as peculiaridades dos sons gerados por determinados instrumentos musicais levou ao desenvolvimento de uma nova ciência, cujas bases repousaram na matemática, física, físiologia, percepção e música. Tal análise histórica denuncia a íntima ligação entre o desenvolvimento da harmonia musical e a busca por uma explicação científica que desse conta de suas bases. A gênese da ciência da acústica foi então impulsionada pela busca por tal fundamentação, que poderíamos sintetizar na seguinte pergunta: porque as combinações de determinados tons são mais agradáveis do que outras? Segundo os historiadores, não há um marco exato de quando se deu o início desta interação entre música e matemática. Contudo, encontramos em Pitágoras, no século VI a.C., provavelmente o registro mais antigo de uma explicação matemática para a relação entre os sons. Utilizando-se de um monocórdio, constrói as relações matemáticas para os intervalos de quarta (3/4 do comprimento total em relação à corda solta), quinta (2/3 do comprimento total em relação à corda solta) e oitava $(1 / 2$ do comprimento total em relação à corda solta), sendo estas relações chamadas de consonâncias pitagóricas. Segundo Abdounur (1999, p. 3),

\begin{abstract}
"A interação entre estas áreas tornase fortemente manifesta a partir da necessidade equacionar e solucionar $\mathrm{o}$ problema da consonância no sentido de buscar fundamentos científicos capazes de justificar tal conceito. As distintas explicações possíveis para consonância/dissonância incluem fatores sócio-culturais, bem como concepções físicas e matemáticas."
\end{abstract}

Desde este primórdio até o desenvolvimento das séries de Fourier e sua utilização, em 1843 por Georg Simon Ohm
(1789-1854), como representação matemática das séries harmônicas, há uma bela história de ligação entre ciência e música, revelando uma gênese multifacetada, com belíssimos episódios, tais como a célebre disputa que ocorreu entre Jean Le Rond d'Alembert (17171783), Leonhard Euler (1707-1783), Daniel Benoulli (1700-1782) e Luigi de La Grange Tournier (1736-1813), em torno da solução matemática do problema da corda vibrante (MONTEIRO JÚNIOR, 1999a, MONTEIRO JÚNIOR, 1999b). A partir daí, sucedeu-se todo um modo de estruturação da ciência da acústica, o desenvolvimento de um conjunto de aparatos experimentais, objetivando a representação gráfica das curvas de timbre e a análise dos harmônicos presentes num som complexo e a gênese do que viria a ser chamada, posteriormente, de psicofísica.

Hoje, quando um músico experimenta as inúmeras possibilidades de um instrumento sintetizador, não dá conta, muitas vezes, de que os softwares estão 'rodando' algoritmos, funções matemáticas no processo de síntese dos timbres que este executante utilizará em suas composições. $\mathrm{O}$ avanço tecnológico, além de permitir a síntese cada vez mais fidedigna dos timbres dos instrumentos tradicionais, abre um infinito número de possibilidades novas na geração de timbres muitas vezes nunca experimentados na música. É tão tal que, hoje, as grandes empresas de instrumentos musicais eletrônicos possuem laboratórios nos quais profissionais trabalham no desenvolvimento de séries harmônicas na geração de novas possibilidades de síntese sonora. A despeito de toda esta história de ligação entre ciência, matemática e música, cuja riqueza poderia gerar interessantes estratégias de ensino do conceito de timbre, as apresentações textuais presentes nos livros didáticos de ciências e matemática sequer fazem referência à existência de tal ligação histórica, não havendo qualquer transposição didática a este respeito.

É nesta vanguarda que vemos a necessidade de refletir sobre estratégias interdisciplinares para o ensino das ciências e da matemática. Neste relato de experiência, procuramos propor duas interessante aplicações para o ensino das progressões geométricas e da 
acústica, utilizando um interessante instrumento musical andino, chamado Zampoña. Para tanto, faremos uma breve descrição do instrumento e uma apresentação da escala cromática ocidental, identificando tal escala como uma progressão geométrica. $\mathrm{Na}$ sequência, analisaremos um exemplar artesanal do citado instrumento, identificando a nota musical de cada tubo e apresentando o desvio percentual em relação ao valor esperado. No final, propomos como atividade prática, a construção de um instrumento similar que possa reproduzir o padrão de intervalos da escala cromática de 12 semitons. A partir da análise da experiência de construção deste conjunto de tubos, podemos refletir sobre a relação entre ciência e cultura, mundo teórico e mundo prático, corporificando aquilo que Paulo Freire $(1981,1983,1987)$ chamou de práxis educativa. Neste sentido, alunos e professores tornam-se seres cognoscentes, objetivando o mundo para entendê-lo e transformá-lo. Neste cenário, a educação científica não deve ser apenas técnica, mas humana e humanizante, voltada para formar cidadãos críticos.

\section{A Zampoña Andina}

A zampoña (siku nos idiomas quechua e aymara) é um instrumento de sopro de origem inca e que se tornou muito conhecido nos países que se situam na região dos Andes, principalmente Peru, Equador e Chile. Nos últimos tempos, tornou-se comum encontrar em feiras de artesanato e praças públicas dos centros urbanos de algumas das grandes metrópoles brasileiras versões de tais instrumentos, principalmente por conta da imigração de bolivianos e peruanos.

A versão mais comum deste instrumento é composta por dois conjuntos de tubos de bambu, dispostos lado a lado e amarrados com cordões, conforme figura abaixo. Cada um dos conjuntos de tubos alcança uma extensão de uma oitava. O conjunto de tubos maior é composto de oito tubos e é chamado de 'Arca'. O outro conjunto é formado por 7 tubos e é chamado de 'Ira'. Contudo, atualmente, podemos encontrar diversas versões alternativas deste instrumento, com números de tubos e tessituras diferentes, como o que utilizamos neste relato de experiência.

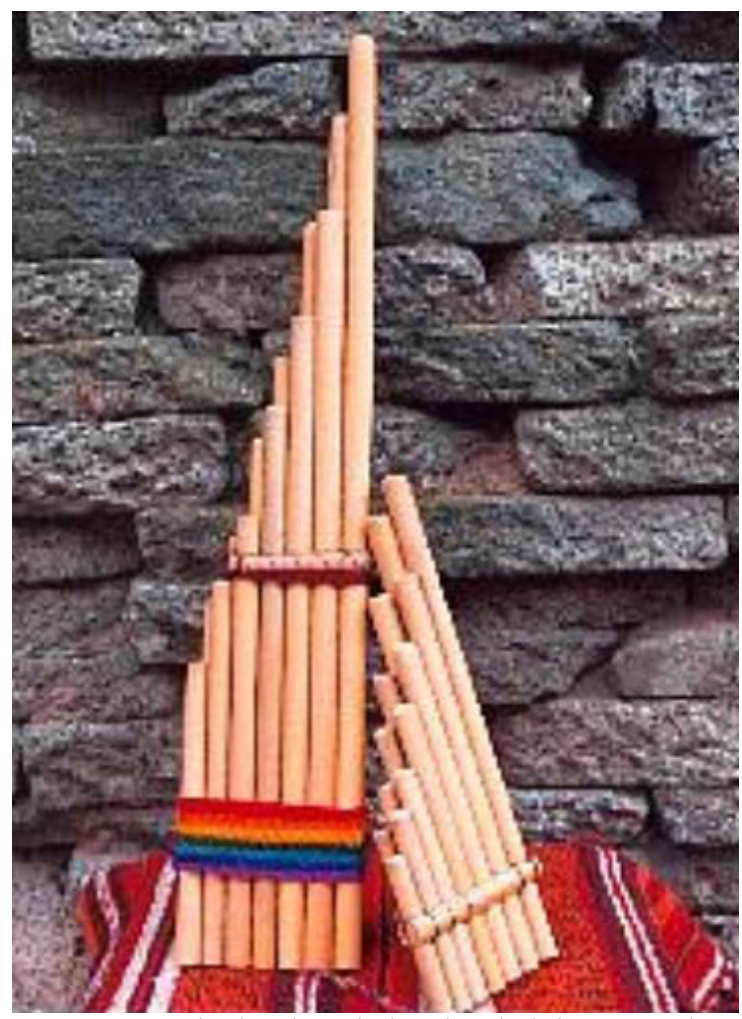

Fonte: user.dankook.ac.kr/ aainst/pds/01-peru.doc 
Não pretendemos aqui apresentar uma descrição detalhada do instrumento, de sua história, nem de sua análise acústica, o que fugiria ao escopo do presente trabalho. Contudo, para maiores detalhes, consultar Arce (1998), Rostworowski (1995) e Baumann (1981).

As duas principais características do "Siku" ou "Zampoña" são o diálogo musical e o uso orquestral e coreográfico que tem suas origens nas culturas Moche e Nasca (300 a.c. 600 d.c.), culturas pré incas da costa do Perú, que depois se estenderam à Bolívia, Equador e Colômbia. Segundo Valência (1981), havia nessa cultura pré inca conjuntos de sikuris similares aos atuais, ou seja, havia grupos musicais coreográficos que interpretavam de modo orquestral as "antaras de cerâmica", enquanto dançavam. Havia personagens "esfolados", dos quais, por alguma razão, tinham como costume extrair os órgãos do rosto (olhos, lábios, etc.), produzindo uma aparência de terror. Personagens que foram representados nas pictografias dos vasos arqueológicos desta cultura, tocando flautas de pan em casais. Daí, tal instrumento foi denominado "siku bipolar moche" como se observa na seguinte figura.

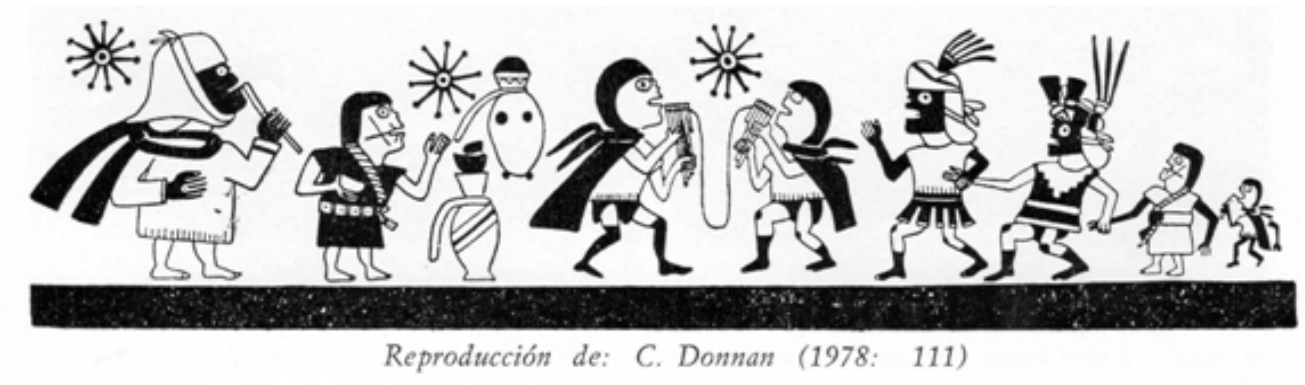

O diálogo musical pode ter se originado quando os músicos solistas se reuniam para tocar flautas de pan em grupo. Tal prática surgiu pela lei do mínimo esforço, quando os músicos se alternavam para interpretar as melodias, necessitando apenas de execuções em pares. A corda que aparece na figura representa tal união entre os pares.

Atualmente, a maioria das zampoñas possui uma escala diatônica e são realmente poucas as que conservam a escala pentatônica pré-colombiana. Porém, nem sempre seu uso é diatônico e é frequente escutar melodias pentatônicas nelas. Aqui é interessante ressaltar o quanto este instrumento se tornou mais popular do que a cultura da qual se originou. Muitos dos grupos de música de imigrantes peruanos e bolivianos que residem no Brasil se apresentam em praças públicas e comercializam CDs com músicas brasileiras e/ou norte americanas e européias em versões instrumentais cujo instrumento solo é a zampoña, ao invés de divulgarem músicas de suas origens.

Para tocar o instrumento, o executante encosta o lábio inferior na extremidade superior do tubo (extremidade aberta do tubo) e sopra tangencialmente a esta abertura. É interessante registrar que mesmo com pequenos exemplares artesanais, com um pouco de treino, é possível tocar algumas melodias simples como atividades para serem executadas por estudantes, como forma de interação em sala de aula. É possível ainda registrar a curva de timbre de instrumentos diferentes num software osciloscópio. Para tanto, existem diversas versões freeware disponíveis na web.

\section{A Escala Cromática e as Progressões Geométricas}

As escalas musicais têm sua origem na música grega antiga. $\mathrm{O}$ seu desenvolvimento alcançou grande avanço no século XVII, 
quando os problemas da harmonia, transposição e modulação das escalas justas, derivadas das consonâncias perfeitas determinadas por Pitágoras, levaram ao desenvolvimento de uma escala musical cujos intervalos eram igualmente espaçados, chamada escala temperada (ROEDERER, 1998, cap. 5). Tal desenvolvimento deu origem a um novo padrão de intervalos na música, patrocinado, dentre outros, pelo eminente músico barroco alemão Johann Sebastian Bach (1685-1750) (CARPEAUX, 1999, p. 86-104), principalmente por meio de seu notório conjunto de obras "O Cravo bem temperado". Bach escreveu diversas obras (prelúdios e fugas) aproveitando as novas possibilidades oferecidas pelo temperamento, tais como, por exemplo, as ilimitadas possibilidades de modulação tonal. Este novo padrão de intervalos resolveu uma limitação herdada dos modos gregos, qual seja a de que não era possível tocar uma mesma música em modos diferentes, ou seja, não era possível transpor de um tom a outro.

Nesta escala temperada, chamada de escala cromática, as doze notas musicais dividem a oitava numa progressão geométrica na qual o $13^{\circ}$ termo (que é a oitava, ou seja, a nota de mesmo nome) possui o dobro da frequência da fundamental (primeira nota). Os fundamentos físicos e matemáticos da divisão do intervalo de oitava numa progressão geométrica (temperamento) serão discutidos agora.

Sabemos que a distinção entre sons, percebida pelo ouvido, ocorre pelo fato de que notas diferentes possuem alturas (frequências) diferentes. Assim sendo, o que caracteriza a qualidade de uma nota pura ser "mais alta" ou "mais baixa" é o fato de ela ter maior ou menor frequência de vibração. Aqui, não podemos confundir com o uso corriqueiro da palavra altura. $\mathrm{Na}$ linguagem popular, este termo é usado para denominar volume, ou seja, a amplitude com que uma fonte sonora vibra, o que está ligado com a quantidade de energia sonora que a fonte emite. Popularmente, quando dizemos "o som está alto", estamos nos referindo ao volume que está alto, quando, cientificamente, deveríamos dizer o "som está intenso", pois trata-se de intensidade e não frequência. Desta forma, quanto mais aguda uma nota, maior sua frequência e quanto mais grave uma nota, menor sua frequência.

Podemos, então, definir o intervalo entre duas notas quaisquer como sendo a razão entre suas frequências. Assim temos $I=f_{2} / f_{1}$. Por exemplo, o intervalo de quinta justa ocorre quando $I=3 / 2$, o de quarta quando $I=4 / 3$ e o de oitava quando $I=2$.

Em música, diz-se que quando duas notas estão separadas por um intervalo de oitava, elas são iguais, e toda escala musical começa e termina na mesma nota musical, separada por um intervalo de oitava, ou seja, começa com uma nota de frequência "f" e termina com a mesma nota, agora com frequência " $2 \mathrm{f}$ ". Podemos, então, dizer que a estrutura harmônica moderna é baseada neste padrão de intervalos, conhecido como escala temperada ou escala cromática. A escala cromática possui doze notas. A décima terceira é chamada oitava, a mesma nota musical da primeira, agora com o dobro da frequência, ou seja, a oitava é o intervalo de altura entre duas notas em que uma delas possui o dobro da frequência da outra. Assim, para construirmos a escala cromática, dividimos o intervalo de oitava, o qual inclui 13 notas musicais, numa progressão geométrica de 13 termos (12 intervalos), criando-se, então, doze intervalos iguais em altura, chamados de semitons. Assim, a frequência de cada nota da escala cromática será $\sqrt[12]{2}$ vezes maior que a sua anterior, definindo, como dissemos acima, uma progressão de razão igual a $\sqrt[12]{2}$. A tabela a seguir mostra a escala cromática iniciando-se no 'Lá' central do piano ( $\left.A_{0}-\mathrm{f}=220 \mathrm{~Hz}\right)$. Observe que são 13 intervalos iguais em altura e não em variação de freqüência, uma vez que o intervalo musical é definido como sendo a razão entre as freqüências de duas notas, e não a diferença entre tais freqüências. 
Francisco Nairon Monteiro Júnior \& Liz Maioly Muñoz Albarracín

Tabela 1: Escala cromática em Lá

\begin{tabular}{|c|c|c|c|}
\hline Nota & $\begin{array}{c}\text { Termos da P.G. } \\
a_{n}=220 \cdot(\sqrt[12]{2})^{(n-1)}\end{array}$ & $\begin{array}{l}\text { Frequência } \\
(\mathrm{Hz})\end{array}$ & Nome do intervalo \\
\hline Lá (A) & $a_{1}=220$ & 220 & Unísono \\
\hline Lá sustenido/Si bemol (A\#/Bb) & $\begin{array}{c}a_{2}=220 \cdot(\sqrt[12]{2})=233,0818 \\
80 \ldots\end{array}$ & 233 & Segunda menor \\
\hline $\mathrm{Si}(\mathrm{B})$ & $\begin{array}{c}a_{3}=220 \cdot(\sqrt[12]{2})^{2}=246,9416 \\
50 \ldots\end{array}$ & 247 & Segunda maior \\
\hline Dó (C) & $\begin{array}{c}a_{4}=220 \cdot(\sqrt[12]{2})^{3}=261,6255 \\
65 \ldots\end{array}$ & 262 & Terça menor \\
\hline Dó sustenido/Ré bemol (C\#/Db) & $\begin{array}{c}a_{5}=220 \cdot(\sqrt[12]{2})^{4}=277,1826 \\
30 \ldots\end{array}$ & 277 & Terça maior \\
\hline Ré (D) & $\begin{array}{c}a_{6}=220 \cdot(\sqrt[12]{2})^{5}=293,6647 \\
67 \ldots\end{array}$ & 294 & Quarta justa \\
\hline Ré sustenido/Mi bemol (D\#/Eb) & $\begin{array}{c}a_{7}=220 \cdot(\sqrt[12]{2})^{6}=311,1269 \\
83 \ldots\end{array}$ & 311 & $\begin{array}{l}\text { Quarta aumentada/ } \\
\text { Quinta diminuta }\end{array}$ \\
\hline Mi (E) & $a_{8}=220 \cdot(\sqrt[12]{2})^{7}=329,6275$ & 330 & Quinta justa \\
\hline Fá (F) & $\begin{array}{c}a_{9}=220 \cdot(\sqrt[12]{2})^{8}=349,2282 \\
31 \ldots\end{array}$ & 349 & $\begin{array}{l}\text { Quinta aumentada/ } \\
\text { Sexta menor }\end{array}$ \\
\hline Fá sustenido/Sol bemol (F\#/Gb) & $\begin{array}{c}a_{10}=220 \cdot(\sqrt[12]{2})^{9}=369,994 \\
422 \ldots\end{array}$ & 370 & $\begin{array}{c}\text { Sexta maior/ } \\
\text { Sétima diminuta }\end{array}$ \\
\hline Sol (G) & $a_{11}=220 \cdot(\sqrt[12]{2})^{10}=391,99$ & 392 & Sétima menor \\
\hline Sol sustenido/Lá bemol (G\#/Ab) & $\begin{array}{c}a_{12}=220 \cdot(\sqrt[12]{2})^{11}=415,30 \\
4697 \ldots\end{array}$ & 415 & Sétima maior \\
\hline Lá (A) & $a_{13}=220 \cdot(\sqrt[12]{2})^{12}=440$ & 440 & Oitava \\
\hline
\end{tabular}

Por exemplo, como podemos ver na tabela, a variação em freqüência da nota 'lá' para a nota 'lá\#' é $233,08 \mathrm{~Hz}-220 \mathrm{~Hz}=13,08 \mathrm{~Hz}$, enquanto que a variação em freqüência da nota 'lá\#' para a nota 'si' é $246,94 \mathrm{~Hz}-23308 \mathrm{~Hz}=13,86 \mathrm{~Hz}$. Se considerarmos a diferença em freqüência do próximo intervalo, 'si' para 'dó', a diferença em freqüência será $261,63 \mathrm{~Hz}-246,94 \mathrm{~Hz}=14,69 \mathrm{~Hz}$. Observe que a diferença em freqüência vai aumentando na medida em que nos deslocamos para o agudo. Contudo, a diferença em altura entre qualquer um destes intervalos de semitom será sempre a mesma, ou seja, $\frac{261,63}{246,94}=\frac{246,94}{233,08}=\frac{233,08}{220}=\sqrt[12]{2}$ e assim por diante.

É importante frisar que tal escala consiste na última etapa de uma longa e interessante história do desenvolvimento do sistema tonal que, infelizmente, em muito ultrapassa o escopo do nosso artigo. Mereceria um trabalho à parte que em muito poderia contribuir para o resgate dos critérios que levaram à aceitação desta divisão de igual temperamento, em detrimento a outras divisões (outros temperamentos) que a antecederam e que, certamente, seria muito proveitoso para a educação científica e musical, pois revelaria alguns sinais do estreito laço mantido ciência e 
música até pouco antes da revolução industrial. Todavia, existem excelentes relatos desta história disponíveis e que podem servir de referência para tal pesquisa em educação (BARBOUR, 1947; BARBOUR, 1948; BARBOUR, 1951; BARNER, 1979; GRENFELL, 2005; LINK JR, 1965). Contudo, um dos critérios para a sua consolidação como sistema ocidentalmente aceito para a divisão da oitava foi sua praticidade, uma vez que permitia a modulação, ou seja, a mudança da tonalidade de uma composição sem prejuízo dos padrões de intervalos de qualquer uma dos graus em relação à tônica, pois a divisão numa progressão geométrica, como mostrado acima, extinguiu as diferenças que existiam entre determinados intervalos quando comparadas tonalidades diferentes. Esta característica do igual temperamento pode ser facilmente discutida em sala de aula utilizando-se, para tanto, de um teclado arranjador ou sintetizador, ou ainda um controlador midi ligado a um computador. Para tanto, uma determinada melodia poderia ser executada em diferentes tonalidades, convidando os ouvintes a perceberem que os intervalos melódicos se mantinham, independentemente da tonalidade em que fosse executada.

\section{Analisando o Instrumento: Primeira Proposta de Atividade}

Utilizamos em nossa oficina uma zampoña adquirida na Colômbia (figura ao lado), construída com tubos de bambu. Por ser um instrumento artesanal, não é construído com o cuidado necessário a ponto de reproduzir com precisão o padrão de intervalos da escala cromática ocidental, como veremos a seguir na análise do instrumento. Escolhemos, propositalmente, um instrumento artesanal por ser mais fácil de encontrar em feiras típicas e por ter um preço mais acessível, em comparação com um instrumento profissional.

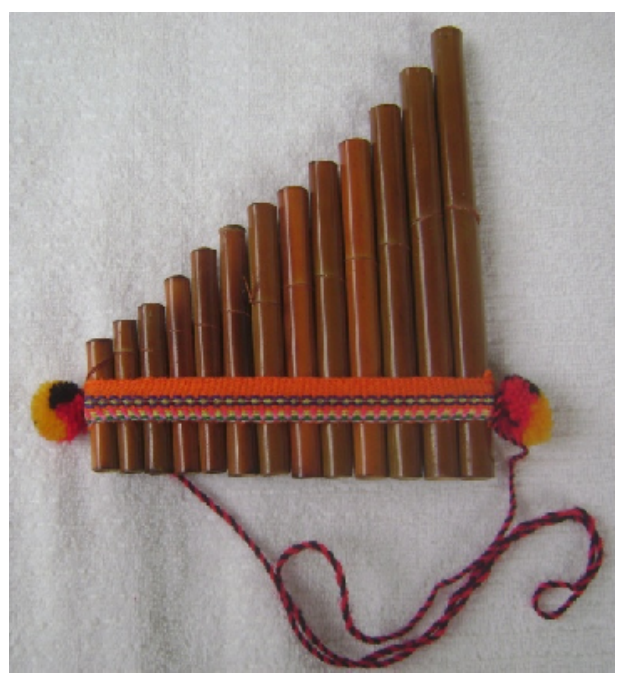

$\mathrm{Na}$ nossa proposta de oficina, apresentamos, inicialmente, a discussão feita acima, acerca da construção da escala cromática. Em seguida, apresentamos o padrão de intervalos das escalas maior e menor natural (MONTEIRO JÚNIOR, 2003), identificando, inclusive, a familiaridade que as pessoas possuem, em geral, com o padrão da citada escala maior. Em seguida, apresentamos a zampoña, identificando a progressão geométrica subjacente aos comprimentos dos tubos. Partindo do tubo de maior comprimento $(16,20 \mathrm{~cm}$, frequência fundamental), calculamos o comprimento ideal (comprimento cromático) dos tubos de um instrumento ideal, no qual o comprimento de cada tubo decresce segundo a progressão geométrica $L_{n}=\frac{L_{0}}{(\sqrt[12]{2})^{(n-1)}}$, numa extensão de duas oitavas. Em seguida, fazemos a medição dos comprimentos reais dos 13 tubos da zampoña 
em questão. Para a medição de tais comprimentos, consideramos apenas o comprimento útil, ou seja, o comprimento total, diminuído da espessura do material que é colocado para fechar a extremidade inferior de cada tubo. Para tanto, medimos apenas 0 comprimento interior do tubo. As medições estão em centímetros e foram arredondadas para duas casas decimais. A tabela a seguir mostra os desvios dos comprimentos dos tubos do instrumento em relação comprimentos cromáticos, calculados a partir do tubo de maior comprimento, o qual emite a nota musical mais grave, de menor frequência.

Tabela 2: Análise dos intervalos da zampoña

\begin{tabular}{|c|c|c|c|c|}
\hline $\mathrm{LT}^{*}(\mathrm{~cm})$ & $\mathrm{LC}^{* *}(\mathrm{~cm})$ & Desvio $(\mathrm{cm})$ & Desvio (\%) & Intervalo aproximado \\
\hline \multirow[t]{2}{*}{16,20} & 16,20 & 0 & 0 & Unísono \\
\hline & 15,30 & & & Segunda menor \\
\hline \multirow[t]{2}{*}{14,55} & 14,43 & $+0,12$ & $+0,83 \%$ & Segunda maior \\
\hline & 13,62 & & & Terça menor \\
\hline \multirow[t]{2}{*}{12.95} & 12,86 & $+0,09$ & $+0,70 \%$ & Terça maior \\
\hline & 12,14 & & & Quarta justa \\
\hline 11,55 & 11,46 & $+0,09$ & $+0,79 \%$ & Quarta aumentada/Quinta diminuta \\
\hline \multirow[t]{2}{*}{10,75} & 10,81 & $-0,06$ & $-0,56 \%$ & Quinta justa \\
\hline & 10,20 & & & Quinta aumentada/Sexta menor \\
\hline 9,75 & 9,63 & $+0,12$ & $+1,25 \%$ & Sexta maior/Sétima diminuta \\
\hline \multirow[t]{2}{*}{9,05} & 9,09 & $-0,04$ & $-0,44 \%$ & Sétima menor \\
\hline & 8,58 & & & Sétima maior \\
\hline 8,20 & 8,10 & $+0,10$ & $+1,23 \%$ & Oitava \\
\hline \multirow[t]{3}{*}{7,40} & 7,65 & $-0,25$ & $-3,27 \%$ & Segunda menor \\
\hline & 7,22 & & & Segunda maior \\
\hline & 6,81 & & & Terça menor \\
\hline \multirow[t]{3}{*}{6,45} & 6,43 & $+0,02$ & $+3,11 \%$ & Terça maior \\
\hline & 6,07 & & & Quarta justa \\
\hline & 5,73 & & & Quarta aumentada/Quinta diminuta \\
\hline \multirow[t]{2}{*}{5,45} & 5,41 & $+0,04$ & $+0,74 \%$ & Quinta justa \\
\hline & 5,10 & & & Quinta aumentada/sexta menor \\
\hline \multirow[t]{2}{*}{4,95} & 4,82 & $+0,13$ & $+2,70 \%$ & Sexta maior/Sétima diminuta \\
\hline & 4,55 & & & Sétima menor \\
\hline \multirow[t]{2}{*}{4,25} & 4,29 & $-0,04$ & $-0,93 \%$ & Sétima maior \\
\hline & 4,05 & & & Oitava \\
\hline
\end{tabular}

*LT: comprimento do tubo; **LC: comprimento cromático (comprimento ideal)

Como podemos observar na tabela, muito embora quase todos os comprimentos dos tubos apresentem desvio em relação ao valor ideal, dá pra arriscar algumas melodias simples, uma vez que tais desvios são pequenos. A utilização de tal oficina em sala de aula aumentou o interesse e envolvimento dos alunos, pois a música e os instrumentos musicais trazem, além do caráter lúdico, uma boa dose de curiosidade. Tal experiência tem se revelado promissora, corroborando com os resultados de pesquisa sobre as potencialidades das propostas interdisciplinares no ensino da matemática.

\section{Construindo um Siku: Segunda Proposta de Atividade}

Com base nos mesmos argumentos discutidos acima, podemos propor a confecção de um siku artesanal, consistindo numa boa oportunidade de refletir sobre a teoria física subjacente ao estudo dos tubos sonoros, modos normais de vibração de um tubo sonoro e a construção de instrumentos musicais de sopro. O desenvolvimento de tais ligações como material didático têm tornado possível, além de uma aula mais reflexiva, unir numa mesma ação educativa ciência e culturalidade. Uma vez que os instrumentos musicais têm suas origens nas culturas, ao longo de suas histórias, seus resgates possibilitam uma práxis na qual tais artefatos podem ser entendidos como objetos culturais, ou como Raymond Murray Schafer (2001) denomina, objetos sonoros, que 
se confundem com as culturas próprias de seus povos. A busca incessante de estratégias para $o$ ensino de ciências e da matemática por meio da culturalidade tem tornado tal ensino mais interessante e palpável, conduzindo a uma relação mais dialética e crítica entre alunos e professores.

De acordo com a teoria acústica, as ondas estacionárias formadas num tubo sonoro ocorrem em duas situações distintas, quais sejam quando apenas uma das extremidades é aberta (tubo fechado) e quando ambas as extremidades são abertas (tubo aberto). No momento, estamos interessados apenas no segundo caso, já que o instrumento musical aqui analisado é formado por tubos abertos. Neste caso, as ondas estacionárias que se estabelecem obedecem a um padrão no qual qualquer harmônico tem um comprimento de onda que é um múltiplo da metade do comprimento do tubo ${ }^{1}$. Assim, as frequências dos harmônicos ${ }^{2}$ que se estabelecerão no tubo estarão de acordo com a relação.

$$
\mathrm{f}_{\mathrm{n}}=\frac{\mathrm{n} \cdot \mathrm{v}}{2 \mathrm{~L}} \quad \text { Sendo } \quad \mathrm{v}=\lambda . \mathrm{f} \quad \Rightarrow \quad \lambda=\frac{2 \mathrm{~L}}{\mathrm{n}}
$$

Na qual 'f' é a freqüência do harmônico, 'n' o número de série do harmônico, 'c' a velocidade do som no meio e ' $L$ ' o comprimento do tubo. Sendo $v=\lambda . f$, temos que $\lambda=\frac{2 L}{n}$. Desta forma, o primeiro harmônico terá um comprimento de onda ' $\lambda$ ' que será o dobro do comprimento do tubo. $\mathrm{O}$ segundo igual ao comprimento tubo, o terceiro a metade de tal comprimento e assim por diante.

Podemos construir um instrumento com 13 tubos, dispondo-os em duas fileiras, sendo a primeira composta por oito tubos (escala maior) e a segunda pelos cinco tubos restantes, conforme mostrado na tabela 3. Para a construção desta flauta artesanal, podemos utilizar bambu, ou ainda tubos de papelão ou plástico com diâmetro em torno de $1,0 \mathrm{~cm}$. Partindo do tubo de menor comprimento, o qual reproduz a nota mais aguda da escala, podemos calcular os comprimentos dos 12 tubos subseqüentes, numa progressão geométrica de razão $\sqrt[12]{2}$.

Podemos escolher o comprimento do menor tubo (maior freqüência) para que seja reproduzido o 'dó' de $512 \mathrm{~Hz}$ no modo fundamental. Neste caso, sendo a velocidade de propagação do som no ar igual a $344 \mathrm{~m} / \mathrm{s}$, a uma pressão de uma atmosfera e a uma temperatura de $20^{\circ} \mathrm{C}$, temos que

$$
\begin{gathered}
v=\lambda \cdot f \quad \Rightarrow \quad 344=512 \cdot \lambda \quad \Rightarrow \\
\lambda=0,671875 \quad \text { metros } .
\end{gathered}
$$

Para o primeiro harmônico temos que

$$
\begin{gathered}
\lambda=2 L \Rightarrow \quad \mathrm{L}=\frac{\lambda}{2} \Rightarrow \quad \mathrm{L}=\frac{0,671875}{2} \Rightarrow \\
\mathrm{L}=0,3359 \text { metros. }
\end{gathered}
$$

\footnotetext{
A condição de que o ventre da onda ocorre exatamente no limite do tubo é apenas uma boa aproximação que torna possível analisar o modelo algebricamente. Rigorosamente, há uma diferença entre o comprimento real do tubo e o comprimento efetivo (RAICHEL, 2006, p. 131-138) e cujo análise matemática só pode ser realizada por meio de equações diferenciais.

2 Para um estudo mais detalhado das séries harmônicas no contexto da construção do conceito de timbre, ver MONTEIRO JÚNIOR (2010).
} 
Francisco Nairon Monteiro Júnior \& Liz Maioly Muñoz Albarracín

Tabela 3: Comprimentos cromáticos do siku artesanal

\begin{tabular}{|c|c|c|c|}
\hline Nota & Termos da P.G. & \multicolumn{2}{|c|}{$\begin{array}{c}\text { Comprimento do tubo } \\
\text { (metros) }\end{array}$} \\
\cline { 3 - 5 } & $\mathrm{L}_{\mathrm{n}}=0,3359 \cdot(\sqrt[12]{2})^{(\mathrm{n}-1)}$ & $\begin{array}{c}\text { Primeira } \\
\text { Fileira }\end{array}$ & $\begin{array}{c}\text { Segunda } \\
\text { Fileira }\end{array}$ \\
\hline $\mathrm{C}$ & $\mathrm{L}_{1}=0,3359$ & 0,3359 & \\
\hline $\mathrm{C} \# / \mathrm{Db}$ & $\mathrm{L}_{2}=0,3359 \cdot(\sqrt[12]{2})^{1}=$ & & 0,3559 \\
\hline $\mathrm{D}$ & $\mathrm{L}_{3}=0,3359 \cdot(\sqrt[12]{2})^{2}=$ & 0,3770 & \\
\hline $\mathrm{D} \# / \mathrm{Eb}$ & $\mathrm{L}_{4}=0,3359 \cdot(\sqrt[12]{2})^{3}=$ & & 0,3995 \\
\hline $\mathrm{E}$ & $\mathrm{L}_{5}=0,3359 \cdot(\sqrt[12]{2})^{4}=$ & 0,4232 & \\
\hline $\mathrm{F}$ & $\mathrm{L}_{6}=0,3359 \cdot(\sqrt[12]{2})^{5}=$ & 0,4484 & \\
\hline $\mathrm{F} \# / \mathrm{Gb}$ & $\mathrm{L}_{7}=0,3359 \cdot(\sqrt[12]{2})^{6}=$ & & 0,4750 \\
\hline $\mathrm{G}$ & $\mathrm{L}_{8}=0,3359 \cdot(\sqrt[12]{2})^{7}=$ & 0,5033 & \\
\hline $\mathrm{G} \# / \mathrm{Ab}$ & $\mathrm{L}_{9}=0,3359 \cdot(\sqrt[12]{2})^{8}=$ & & 0,5332 \\
\hline $\mathrm{A}$ & $\mathrm{L}_{10}=0,3359 \cdot(\sqrt[12]{2})^{9}=$ & 0,5649 & \\
\hline $\mathrm{A} \# / \mathrm{Bb}$ & $\mathrm{L}_{11}=0,3359 \cdot(\sqrt[12]{2})^{10}=$ & & 0,5985 \\
\hline $\mathrm{B}$ & $\mathrm{L}_{12}=0,3359 \cdot(\sqrt[12]{2})^{11}=$ & 0,6341 & \\
\hline $\mathrm{C}$ & $\mathrm{L}_{13}=0,3359 \cdot(\sqrt[12]{2})^{12}=$ & 0,6718 & \\
\hline
\end{tabular}

Tais propostas de atividade, além de aproximarem ciência e música, podem, uma vez resgatados os referenciais adequados, introduzir a culturalidade nas aulas de ciências. Uma destas possibilidades materializa-se a partir da análise de instrumentos musicais característicos de determinadas culturas, como é o caso da zampoña, analisada no presente artigo. Por outro lado, a análise das escalas musicais pode revelar intervalos característicos de determinadas culturas, tornando possível uma análise interdisciplinar, útil tanto ao ensino das ciências quanto ao ensino de música.

A proposta de trabalho aqui apresentada também é aplicável à construção de outros instrumentos musicais, servindo inclusive para intervenções em situações da educação musical. Os cálculos dos comprimentos cromáticos aplicados à zampoña podem ser utilizados na construção de outros instrumentos de sopro, bem como marimbas de vidro e xilofones. Neste sentido, parece-nos bastante claro que a pesquisa em educação numa proposta interdisciplinar como a aqui apresentada não só é útil e rica para a educação científica, mas também pode revelar ligações possíveis de serem utilizadas pelo professor de música.

\section{Reflexões Interdisciplinares em Matemática e Música}

Para se entender o fenômeno sonoro como um todo é necessária uma leitura que se estenda para muito além do universo do som como onda mecânica, um universo no qual os mundos físico, matemático, físiológico e psicológico amalgamam-se como necessidade primeira para tentar abarcar esta realidade. Seria desta forma um andar contrário à especialização, à fragmentação, tentando aprender os passos que a própria história ensinou. Segundo Libâneo (2005, p.38),

"Uma das características do novo paradigma de ciência é a interdisciplinaridade, que alguns preferem 
chamar de "inter-relação entre os saberes científicos". Há muitas interpretações da interdisciplinaridade, mas poder-se-ia vê-la numa perspectiva epistemológica integração entre os saberes contra a fragmentação disciplinar - e numa perspectiva instrumental - busca de um saber útil, aplicado, para enfrentamento de problemas e dilemas concretos.".

Desta forma o aprendizado deve transpor os limites da escola, para além dos objetivos dos testes de aprendizado. Deve servir para o cidadão comum, capacitá-lo para agir conscientemente, decidir, analisar. Para isto, é necessária uma formação escolar na qual problemas reais sejam geradores das atividades, motivadores do aprendizado. É preciso buscar uma leitura dos problemas a partir de uma consciência mais ampla e que só pode ser construída se as diversas linguagens forem ensinadas como partes de um mesmo todo. Muitas vezes, a incapacidade de um indivíduo de atuar conscientemente frente aos desafios e problemas da vida se dá por ele não perceber que os conhecimentos escolares adquiridos, as experiências vividas e os aprendizados delas extraídos reportam-se a uma mesma realidade e que juntar estes dois mundos é tarefa de cada ser consciente. Contudo cabe à escola promover o encontro dos mundos, criar o ambiente necessário para que o aluno possa agir conscientemente na construção de sua leitura do mundo. Muito embora ainda em pequena quantidade, há interessantes relatos de propostas interdisciplinares para o ensino de ciências e matemática por meio da música, que podem ser utilizadas pelos professores em suas aulas ou ainda servirem de guias para o desenvolvimento de outras tantas (ABDOUNUR, 1999, BARRETT, 2001; MONTEIRO JÚNIOR, 2003; ROGERS, 2004; ROSENBLOOM, 2004).

\section{Conclusões}

Serão grandes os desafios para aquele professor que decidir sair do mundo 'pronto' dos exercícios dos livros didáticos, em direção a um modo de ensinar ligado com a realidade.
Além da dificuldade própria da necessidade de um conhecimento interdisciplinar, fruto de uma formação igualmente compartimentalizada, encontrará muitas vezes a barreira da escassez de referências nacionais sobre o tema. Contudo, a aventura está exatamente aí: aprender para além das fronteiras dos livros didáticos para, então, ensinar. Buscar o diálogo entre as diversas linguagens, identificando os problemas históricos que deram origem a estas ligações como, por exemplo, a relação entre escalas musicais e progressões geométricas, discutida neste trabalho.

\section{Referências}

ABDOUNUR, O. J. Matemática e música: o pensamento analógico na construção de significados. 1. ed. São Paulo: Escrituras, 1999, $315 \mathrm{p}$.

ARCE, J. P. Sonido rajado: the sacred sound of chilean pifilca flutes. The Galpin Society Journal, v. 51, p. 17-50, 1998.

BARBOUR, J. M. Bach and "The Art of Temperament". The Musical Quarterly Oxford University Press, Cary, NC, USA, v. 33, n. 1, p. 64-89, jan. 1947. Disponível em: $<$ http://www.jstor.org/stable/739436>. Acesso em: 26 nov. 2009. eISSN 1741-8399.

Irregular Systems of Temperament.

Journal of the American Musicological Society - American Musicological Society, Brunswick, ME, USA, v. 1, n. 3, p. 20-26, 1948. Disponível em: $<$ http://www.jstor.org/stable/830012>. Acesso em: 30 nov. 2009. ISSN 0003-0139.

Tuning and Temperament: a historical survey. East Lansing, MI, USA: Michigan State College Press, 228 p., 1951. ISBN-10: $0306704226 . \quad$ ISBN-13: $978-$ 0306704222.

BARNES, J. Bach's Keyboard Temperament: Internal Evidence from the Well-Tempered Clavier. Early Music - Oxford University Press, Cary, NC, USA, v. 7, n. 2, p. 236-249, $1979 . \quad$ Disponível em: $<$ http://www.jstor.org/stable/3126342>. Acesso em: 26 nov. 2009. eISSN 1741-7260. 
BARRETT, J. R. Interdisciplinary work and musical integrity. Music Educators Journal, v. 87, n. 5, p. 27-31, mar. 2001.

BAUMANN, M. P. Music, dance, and song of the Chipayas. Latin American Music Review, v. 2, n. 2, p. 171-222, 1981.

CARPEAUX, O. M. Uma nova história da música. Rio de Janeiro: Ediouro, 1999.

FREIRE, P. Ação cultural para a liberdade. $5^{\text {a }}$ ed. Rio de Janeiro: Paz e Terra, 1981.

. Extensão ou comunicação? Tradução de Rosisca Darcy de Oliveira. Prefácio de Jacques Chonchol. $7^{\text {a }}$ ed. Rio de Janeiro: Paz e Terra, 1983.

Pedagogia do oprimido. $17^{\mathrm{a}}$ Ed. Rio de Janeiro: Paz e Terra, 1987.

GRENFELL, M. T. The development of the equal temperament scale: Evolution or radical change? Dissertação. Western Connecticut State University, Danbury, Connecticut, September 2005. Disponível em: $<\mathrm{http}$ //thesis.grenfellmusic.net/>. Acesso em: 01 mai. 2011.

LIBÂNEO, J. C. As teorias pedagógicas modernas revisitadas pelo debate contemporâneo na Educação. In: LIBÂNEO, J. C.; SANTOS, A. (Org.). Educação na era do conhecimento em rede e transdisciplinaridade. Campinas: Alínea, 2005. p. 19-62.

LINDSAY, R. B. The story of acoustics. The Journal of Acoustical Society of America, New York, v. 39, n. 4, p. 629-644, abr. 1966.

LINK JR, J. W. Understanding the Two Great Temperaments: Equal and Meantone. Journal of Research in Music Education - The National Association for Music Education, Reston, VA, v. 13, n. 3, p. 136-146, 1965. Disponível em: $<$ http://www.jstor.org/stable/3343668?origin=J STOR-pdf $>$. Acesso em: 26 nov. 2009. eISSN 1945-0095.

MONTEIRO JÚNIOR, F. N.; MEDEIROS, A. J. G. A matematização da corda vibrante no século XVIII. In: ENCONTRO PERNAMBUCANO DE EDUCAÇÃO MATEMÁTICA, 4, 1999, Recife/PE. Atas... Recife: SBEM, 1999a.

; MEDEIROS, A. J. G. O século XIX e as séries de Fourier. In: ENCONTRO
PERNAMBUCANO DE EDUCAÇÃO MATEMÁTICA, 4, 1999, Recife/PE. Atas... Recife: SBEM, 1999b.

et al. Matemática e música: as progressões geométricas e o padrão de intervalos da escala cromática. Bolema, Rio Claro, ano 16, n. 20, p. 101-126. 2003.

MONTEIRO JÚNIOR, F. N. Somando funções trigonométricas: uma reconstrução didática do conceito de timbre a partir de duas experiências pedagógicas. Bolema - Boletim de Educação Matemática, Rio Claro/SP, n. 37, v. 23, 2010. ISSN 1980-4415.

RAICHEL, D. R. The science and applications of acoustics. 2 ed. New York: Springer, 2006. ISBN-10: 0-387-26062-5.

ROEDERER. J. G. Introdução à física e psicofísica da música. 1. ed. São Paulo: EDUSP, 1998, 312 p.

ROGERS, G. L. Interdisciplinary lessons in musical acoustics: the science-math-music connection. Music Educators Journal, v. 91, n. 1, p. 25-30, sep., 2004.

ROSSING, T. D. The science of sound. 2 ed. Massachusetts: Addison-Wesley, 1990.

ROSENBLOOM, A. F. High school music studies and social studies: an interdisciplinary approach. Music Educators Journal, v. 90, n. 3, p. 41-45, jan. 2004.

ROSTWOROWSKI, M. Historia del tahuantinsuyo. Instituto de Estudios Peruanos. IEP Ediciones. Lima, 1995.

SCHAFER, R. M. A afinação do mundo uma exploração pioneira pela história passada e pelo atual estado do mais negligenciado aspecto do nosso ambiente: a paisagem sonora. Tradução: Maria Trench Fonterrada. São Paulo: Editora da UNESP, 2001. ISBN 85-7139-3532.

VELENCIA CH AMÉRICO. El siku bipolar altiplanico. Vol. I. Los sikuris y pusamorenos. Con una colección de 35 recopilaciones de música dialogal. Lima: Taller de Música Hatarisun, 1983.

VELENCIA CH AMÉRICO. Los sikuris de la isla de Taquille. Separata del Boletín de Lima. Lima 1981. 